\title{
REMOVAL OF FE (II) AND MN (II) FROM WASTEWATER USING NANO- CHITOSAN PREPARED FROM SHRIMP WASTE
}

\author{
Gamal M. Elkady ${ }^{(1)}$, Hazem Fathallah ${ }^{(1)}$, Moustfa Abo Elfadl ${ }^{(2)}$, Mohamed Elsayed ${ }^{(2)}$, Atef Selim \\ (1) Applied chemistry Dept., Faculty of science, Al Azhar university \\ (2) Water Desalination \& Treatment Unit, Hydrogeochemistry Dept., Desert Research Center
}

\begin{abstract}
The aim of present study is to find an economic way for water treatment to remove iron and manganese ions usin-g nano chitosan NCS. The chitosan prepared from shrimp waste characterized by FT-IR spectroscopy and $X$-Ray Diffraction XRD. It's molecular weight M.wt. and degree of acetylation DA also determined, it's removal enhanced by decreasing the size in the nano size form using ionic gelation method with sodium tripolyphosphate TPP. The morphology of the nano chitosan particles were studied using Scanning Electronic Microscopy SEM and Transmission electron microscopy TEM, pattern and investigate the adsorption properties of Nano chitosan for the removal of Fe(II) and Mn (II) ions from the aqueous phase in a batch equilibrium system. The different variables affecting the adsorption capacity such as contact time, pH of the sorption medium, and initial metal ion concentration in the feed solution were investigated on a batch adsorption basis. The maximum adsorption capacity of Fe (II) and Mn(II) was 99.8 and from 95.3\%, respectively at $5 \mathrm{~g}$ of the adsorbent dose after 20 minutes.
\end{abstract}

Keywords (chitosan -nanoparticles- characterization -ionic gelation-ion removal- adsorption- water)

\section{INTRODUCTION}

Heavy metals are one of the most important categories of water pollutants, where they can be leached from their bearing rocks into groundwater Heavy metals are also produced during industrial activities and causes soil and water contamination[1]. Iron and manganese are metallic elements present in many types of rock. They are mostly present in the soluble reduced divalent form as ferrous $\mathrm{Fe}(\mathrm{II})$ and manganous $\mathrm{Mn}(\mathrm{II})$ ions. Both iron and manganese impart a strong metallic taste to the water, both cause staining and their accumulation have harmful effects on human body [2, 3]. Iron and manganese removal from water is recommended when the dissolved concentrations exceed $0.3 \mathrm{mg} / \mathrm{L}$ iron Fe(II) and $0.05 \mathrm{mg} / \mathrm{L}$ manganese $\mathrm{Mn}(\mathrm{II})$ [3]. Despite of presence of simple traditional methods for removal of heavy metals ions from wastewater Filtration, Chemical precipitation, Ion exchange, and Membrane technologies [4,5], the adsorption has been considered as one of the most efficient methods with many advantages including low cost, high efficiency, good selectivity and recyclability with various materials[6]. recently; low-cost adsorbents that are produced from wastes have been used widely[7]. Chitosan has the ability to adsorb significant amounts of metal ions over a wide range $[4,8]$. Chitosan is a natural, nontoxic, biodegradable, and biocompatible polymer with antibacterial activity and has a wide range of applications in different fields such as membranes, medicine, drug delivery, hydrogels, water treatment, adhesives, food packaging, fuel cells, and surface conditioner [9].Chitosan can be prepared from shrimps and crabs waste throw several steps involves demineralization with acid solution, deprtonization with alkaline solution and deacetylation with a concentrated alkaline solution [10]. However; Chitin is made up of a linear chain of acetyl glucosamine groups while chitosan is obtained by removing enough acetyl groups $\left(\mathrm{CH}_{3}-\mathrm{CO}\right)$ for the molecule to be soluble in most diluted acids.[11] The molecular weight(M.wt) and degree of deacetylation(DA) 
can be modified during its preparation to obtain free amine as well as hydroxyl groups in chitosan structure [12]. It is known that chitosan is a weak base, insoluble in water and organic solvents, however, it is soluble in dilute aqueous acidic solution ( $\mathrm{pH}<6.5)$, which can convert the glucosamine units into a soluble form of protonated amine $\left(\mathrm{R}-\mathrm{NH}_{3}{ }^{+}\right)[13]$. The adsorption capacity of chitosan or even natural polymer can be controlled by sorbent particle size, i.e. preparation of chitosan at nanoscale, because of unique size and large surface-tovolume ratio [14]. Among the variety of methods developed to prepare chitosan nanoparticles, ionic gelation technique has attracted considerable attention due to this process is non-toxic, organic solvent free, convenient and controllable[15]. Chitosan nanoparticles are formed in the ionic gelation due to the electrostatic interaction between the positively charged amine group of chitosan and negatively charge group of polyanion such as tripolyphosphate (TPP ) [14].The advantage of the ionic gelation process is that desired size and surface charge can be modulated by right control of critical processing parameters such as chitosan to TPP weight ratio, $\mathrm{pH}$, and concentration of chitosan and TPP solutions, etc. to fabricate the nanoparticle structure with optimum antimicrobial activity[16]. TPP has also been selected as a possible crosslinking agent for the preparation of chitosan nanoparticles because of its coagulation and neutralization effect.

In this work, an effective adsorbent chitosan nanoparticles were extracted from shrimp shell waste and using it in the removal of Fe(II) and Mn (II) ions from wastewater as there is a few paper used chitosan nanoparticles as an adsorbent for Fe (II) and Mn(II) removal. However; chitosan nanoparticles were prepared by ionic gelation technique in presence of TPP as crosslinker and characterized using FT-IR, $\mathrm{XRD}, \mathrm{SEM}$, and zeta sizer, the adsorption kinetics, adsorption isotherm (Langmuir and Freundlich) were studied.

\section{EXPERIMENTAL AND MATERIAL}

\subsection{Materials}

Local shrimp waste was collected and immediately washed several times with water and detergent then allowed to dry in open area under sunlight then grounded to small particles. The grounded material was transformed into chitosan via three successive steps (demineralization, deproteinization, and deacetylation).,Tripolyphosphate,acetic acid, Sodium hydroxide $\mathrm{NaOH}$, Hydrochloric acid $\mathrm{HCl}$, acetic acid glacial, Ferrous sulfate heptahydrate and Manganese chloride hydrate, Purchased from a local chemical company.

\subsection{Methods}

\subsubsection{Extraction of chitosan from chitin}

Firstly; demineralization and deproteinization to remove primarily calcium carbonate and disrupt the chemical bonds between chitin and proteins were generally performed by acid treatment technique using $1 \mathrm{M} \mathrm{HCl}(1: 10 \mathrm{w} / \mathrm{v})$ and $1 \mathrm{M} \mathrm{NaOH}(1: 10 \mathrm{w} / \mathrm{v})$ for $24 \mathrm{~h}$ for each at room temperature, respectively [11]. After that, the solution was filtered and the residue was washed several times with deionized water (DI) until neutral pH. However; demineralization was easily achieved because of decomposition of calcium carbonate into the water-soluble calcium salts with the release of carbon dioxide as shown in the following equation; $[10,17,18]$.

$$
2 \mathrm{HCl}+\mathrm{CaCO}_{3} \rightarrow \mathrm{CaCl}_{2}+\mathrm{H}_{2} \mathrm{O}+\mathrm{CO}_{\mathbf{2}} \uparrow
$$

To convert chitin to chitosan, the acetyl groups were removed during the de-acetylation process, where demineralized chitin was transferred to a $60 \%$ sodium hydroxide solution. Then the solution was boiled for $2 \mathrm{~h}$ after that alkali solution was drained off and washed repeatedly with DI till $\mathrm{pH}$ was lowered to normal. Finally, chitosan was further dried at room temperature and stored for further uses [19].

\subsubsection{Preparation of chitosan nanoparticles}

Chitosan nanoparticles were prepared by dissolving at $0.5 \mathrm{~g}$ of prepared chitosan in 100 $\mathrm{ml}$ of $1 \%$ acetic acid $(\mathrm{v} / \mathrm{v})$, and the $\mathrm{pH}$ of the solution was adjusted to be $4.6 \sim 4.8$ using $1 \mathrm{~N}$ 
$\mathrm{NaOH}$. Chitosan nanoparticles were formed spontaneously upon addition of $3 \mathrm{ml}$ chitosan solution under vigorous magnetic stirring to 1 $\mathrm{ml}$ of an aqueous TPP solution $(0.25 \% \mathrm{w} / \mathrm{v})$, with a ratio of chitosan to TPP 3:1 at room temperature. Nanoparticles were separated by centrifugation at $9000 \times \mathrm{g}$ for $20 \mathrm{~min}$ [20]. Chitosan nanoparticles were extensively rinsed with DI to remove any $\mathrm{NaOH}$ residues and dried at $40 \mathrm{C}^{\circ}$ for $24 \mathrm{~h}$ before further use or analysis [21].

\section{CHARACTERIZATION}

\subsubsection{Characterization of chitosan}

\subsubsection{Ash value}

To determine the ash value of chitosan, $1.0 \mathrm{~g}$ of chitosan sample is placed and accurately weighed into clean, dry, pre-weighed porcelain crucible. The samples are heated in a muffle furnace preheated to $650^{\circ} \mathrm{C}$ for $4 \mathrm{hr}$. The crucibles are allowed to cool in the furnace to less than $200^{\circ} \mathrm{C}$ and then placed into desiccators with a vented top. Percentage of ash value is calculated using the following[22]

$$
A \operatorname{sh} \%=\frac{\left(W_{1}-W_{2}\right)}{W_{1}} \times 100
$$

Where, $W_{1}$ and $W_{2}$ in grams are the weight of chitosan before and after ignition, respectively

\subsubsection{Determination of degree of deacetylation:}

The degree of deacetylation (DA) was measured by the acid-base titration method with modifications. In brief, Chitosan (0.1 g) was dissolved in $30 \mathrm{ml} \mathrm{HCl}$ aqueous solution $(0.1 \mathrm{~mol} / \mathrm{l})$ at room temperature with $2-3$ drops of methyl orange added. The red chitosan solution was titrated with $0.1 \mathrm{~mol} / \mathrm{l} \mathrm{NaOH}$ solution until it turned orange. The DD was calculated by the formula

$$
D D \%=\frac{\left.C_{1} V_{1}-C_{2} V_{2}\right)}{M \times 0.0994} \times 0.016
$$

Where, $\mathrm{C}_{1}=$ concentration of standard $\mathrm{HCl}$ aqueous solution $(\mathrm{mol} / \mathrm{l}), \mathrm{C}_{2}=$ standard $\mathrm{NaOH}$ solution $(\mathrm{mol} / \mathrm{l}), \mathrm{V}_{1}=$ volume of the standard $\mathrm{HCl}$ aqueous solution used to dissolve chitosan $(\mathrm{ml}), \mathrm{V}_{2}=$ volume of standard $\mathrm{NaOH}$ solution consumed during titration $(\mathrm{ml})$, and $\mathrm{M}=$ weight of chitosan (g). The number 0.016 (g) is the equivalent weight of $\mathrm{NH}_{2}$ group in $1 \mathrm{ml}$ of standard $1 \mathrm{~mol} / \mathrm{l} \mathrm{HCl}$ aqueous solution and 0.0994 is the proportion of $\mathrm{NH}_{2}$ group by weight of chitosan[23].

\subsubsection{Determination of molecular weight}

Viscosity was assessed using a Brookfield viscometer, Model DV3THBCJ0 (Brookfield Engineering Labs, made in USA). In brief, $1 \%$ chitosan solution was prepared using $1 \%$ acetic acid. The Measurement was made using a No. 5 spindle at $50 \mathrm{rpm}$ at $25 \mathrm{C}^{\circ}$ with values reported in centipoises (cps) units[24].Intrinsic viscosity was used to calculate the viscosity average molecular weight for the prepared samples from the Mark-Houwink Sakurada equation:

$$
\eta=\mathrm{KM}^{\mathrm{a}}
$$

where $\mathrm{K}$ and a are the constants for a given solute-solvent system is 0.078 and 0.76 , respectively[24, 25].

\subsubsection{FT-IR spectroscopy and XRD}

FT-IR spectroscopy (Jasco FT-IR 6100 ,made in Japan) was used to compare and confirm the chemical conformation of standard chitosan with that of extracted chitosan. The spectra of chitosan samples were obtained with a frequency range of $\lambda=400-4000 \mathrm{~cm}$ [26]. The wide-angle X-ray diffraction (XRD) analysis was applied to detect the crystallinity of chitosan and nano-chitosan prepared and their patterns were recorded using PAN analytical XRD X'pert PRO).

\subsection{Characterization of chitosan Nanoparticles.}

The particle size distribution, The zeta potential and polydispersity index (PDI) of the chitosan nanoparticles were determined by dynamic light scattering (DLS) using a Zetasizer Nano instrument (Malvern Instruments, U.K.)Transmission electron microscopy (TEM) was used to examine size, shape, and morphologies of the nanoparticles prepared in this study. TEM micrographs of nanoparticle samples deposited on copper grids were obtained with a (JEOL-2100 Electron 
GAMAL M. ELKADY, et al.

Microscope), made in Japan.Scanning electron microscope(SEM) analysis is employed to determine the morphology of formed nanoparticle using (Quanta FEG250 SEM FEI company ) SEM gives high-resolution images of the surface of a sample.

\section{METAL ION UPTAKE EXPERIMENTS 4.1 Batch adsorption experiment}

Batch adsorption experiments were conducted in two series of $150 \mathrm{ml}$ beakers with $100 \mathrm{ml}$ of iron and manganese solution at a certain concentration. The initial $\mathrm{pH}$ of solutions was adjusted using the required amounts of $0.1 \mathrm{M} \mathrm{HCl}$ or $0.1 \mathrm{M} \mathrm{NaOH}$ solutions. The mixture was equilibrated with nanochitosan at a rotation speed of $180 \mathrm{rpm}$ in a shaker for $120 \mathrm{~min}$. All experiments were conducted at room temperature. Samples were taken at fixed time intervals to determine solution concentration. Iron and manganese concentrations in the filtrates were analyzed by ICP (ICAP 6500 Duo,thermo scientific England) A series of experiments were conducted to determine the effect of parameters such as adsorbent dose, $\mathrm{pH}$, initial concentration, and contact time on equilibrium uptake of Fe (II)and Mn(II) ions by NCS. [27]Adsorption experiments for the removal of Fe (II)and $\mathrm{Mn}$ (II) ions were conducted in $\mathrm{pH}$ range of (2.5-7), adsorbent dosage (0.5-15 g/l), contact time from (0-120) min, metal concentration $(10-120 \mathrm{mg} / \mathrm{l})$ at room temperature. The adsorption kinetics and isotherms data were collected under the optimized condition of adsorbent dose, $\mathrm{pH}$, and contact time. After separation by centrifugation (model) at $5000 \mathrm{rpm}$, the residual concentration of the metal ions was determined by ICP. In all of the above experiments, the adsorption values were calculated from the change in solution concentration using the following equation.[28]

$q=\left(C_{0}-C_{e}\right) \times \frac{V}{M}$

where $\mathrm{q}$ is the amount $(\mathrm{mg} / \mathrm{g})$ of metal ions adsorbed by the NCS, $\mathrm{C}_{o}$ and $\mathrm{C}_{\mathrm{e}}(\mathrm{mg} / \mathrm{l})$ are the metal concentrations in the solution initially and after adsorption, respectively, $\mathrm{V}$ is the volume of added solution and $\mathrm{m}(\mathrm{g})$ is the mass of the adsorbent (dry) used. The removal efficiency calculated as:

$R \%=100 \times \frac{C_{o}-C_{e}}{C_{o}}$

5. RESULT AND DISCUSSION:

5.1. Characterization of chitosan and chitosan nanoparticles:

Chitosan produced from shrimp has been prepared at three molecular weights, high M.wt (51269.68 Dalton), medium M.wt (32403.67 Dalton) and low M.wt (3923 Dalton). The difference in M.wt of the obtained polymer was due to heating of the reaction temperature and time.[17] This is because the continuous heating of the polymer during the deacetylation process with $\mathrm{NaOH}$ causes a decrease in the molecular weight with the rising in the deacetylation degree.[25]. Based on the data produced from particle size analyzer, it was found that the lowest M.wt was chosen to be easier to resize it in the nano form, where the produced nanoparticle size was $331 \mathrm{~nm}$, while the particle size of that produced from medium and high M.wt were 1562 and 3914 nm, respectively, Table 1 . This is because of as the molecular weight decreased, the particle size also decreased the larger molecular size [29]. DA of chitosan and ash content of chitosan were $75 \%$ and $4 \%$, respectively. It is known that DA is the most parameter used for chitosan characterization, and is defined as the number of amines group in relation to the number of amides group of the polymeric chain formed as a result of removing $-\mathrm{CO}-\mathrm{CH}_{3}$ group from the chitin chain as shown in scheme (1). DA of chitosan may affect the adsorption properties for application in water and wastewater treatment, the obtained medium DA $75 \%$ confirm that the prepared chitosan can be used as an effective adsorbent for some heavy metals [30].

Scheme (1) chitin deacetylation and chitosan structure

The structure of the prepared chitosan from chitin was confirmed by FT-IR Fig.1(b). 


\begin{tabular}{cccc}
\hline \hline Type & M.wt(D) & Size (nm) & pdI \\
\hline High M.wt chitosan & 51269.68 & 3914 & 0.271 \\
\hline Mid M.wt chitosan & 32403.67 & 1562 & 0.898 \\
\hline Low M.wt chitosan & 3923 & 331 & 0.331 \\
\hline \hline
\end{tabular}

Fig. (2) that showed roughly spherical in shape [35]. Fig. (3) shows SEM images of chitosan nanoparticles show the morphology of the nanoparticles .Findings show that the particles size of chitosan and pdI as shown in Table1 [36]

Table 1. The particle size and Pdl for nano chitosan at different M.wt.

\section{L. Factors atfectung on Adsorption}

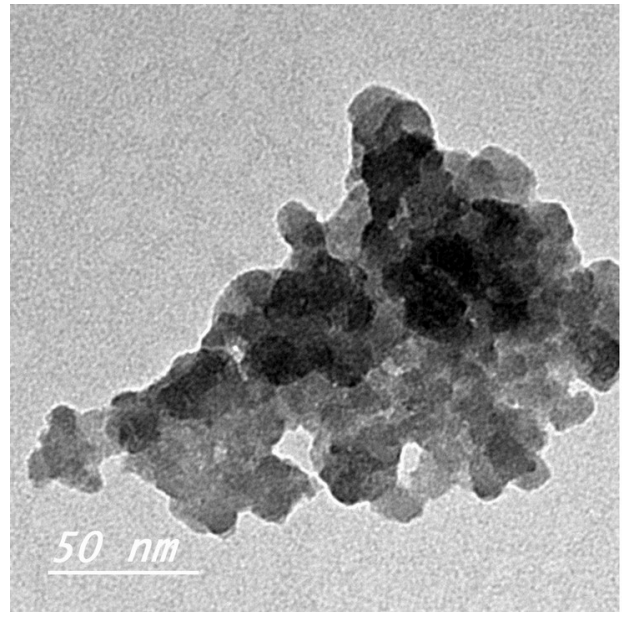

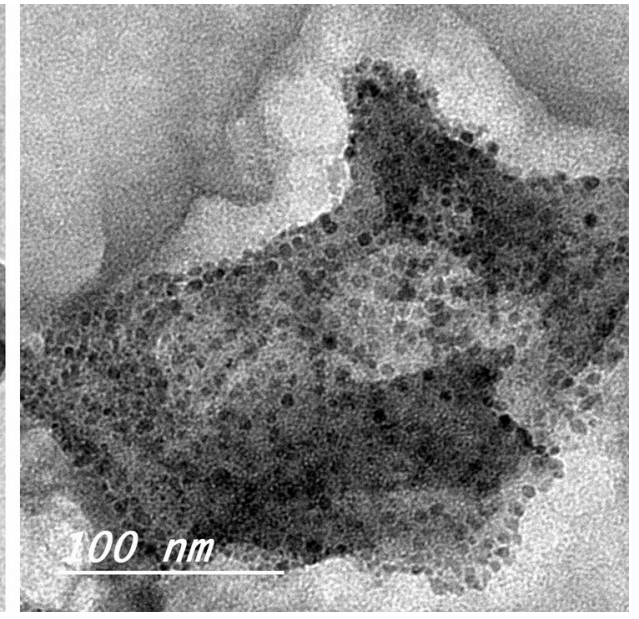

Fig.2. TEM images of chitosan nanoparticles at 50 and $100 \mathrm{~nm}$. be taken in consider which explain how fast the chemical reaction occurs and also provide information on the factors affecting the reaction rate. two kinetic models used pseudo-firstorder kinetic model and pseudo-second-order kinetic model .we used the previous factor to study the adsorption of Fe (II)and Mn(II) ions onto NCS using batch experiments [32].

Speciation of heavy metal ions and surface charge of adsorbent depends mainly upon $\mathrm{pH}$ of the solution. Hence, it is customary to study the effect of $\mathrm{pH}$ on adsorption efficiency for sorption studies [37]. However; $\mathrm{pH}$ must be less than that at which metal ions precipitate, i.e. $\mathrm{pH} 6$ for iron and 8 for $\mathrm{Mn}$, [38].The effects of $\mathrm{pH}$ on the removal of Fe (II) and Mn (II) were studied with the $\mathrm{pH}$ ranges of $2.5 \pm 0.2$ to $7 \pm 0.2$ with keeping other parameters constant,

Fig.4 (a).

Adsorption is separation processes in which some materials (adsorbate) are adhere from a bulk gas or liquid phase onto the surface of a porous solid (adsorbent). Batch studies use the fact that the adsorption phenomenon at the solid/liquid interface leads to a change in the concentration of the solution. Adsorption isotherms are constructed by measuring the concentration of adsorbate in the medium before and after adsorption at a fixed temperature with other different parameter such as initial concentration, adsorbent dose, contact time and $\mathrm{pH}$. Several isotherm models used to describe adsorption such as Langmuir and Freundlich model can describe the distribution of metal ions on the surface of the solid phase of adsorbent. the adsorption rate is another important factor and adsorption kinetics must
From the figure, the optimum adsorption takes place at $\mathrm{pH} 4$ for Fe (II) and at $\mathrm{pH} 6$ for $\mathrm{Mn}$ (II), where the removal percent was 81.3 and 81.1, respectively. Further increase in $\mathrm{pH}$ leads to the precipitation of $\mathrm{Fe}$ (II) which inhibits the adsorption process. While, at low $\mathrm{pH}$ values, chitosan is positively charged with higher $\mathrm{H}^{+}$ ion concentration, which led to protonation of amino groups that induces an electrostatic repulsion of metal cations that reduces the number of binding sites available for metallic ions [32]. In general, Fe (II) and Mn (II) ions uptake increases as the $\mathrm{pH}$ increases until to $\mathrm{pH}$ 7. 


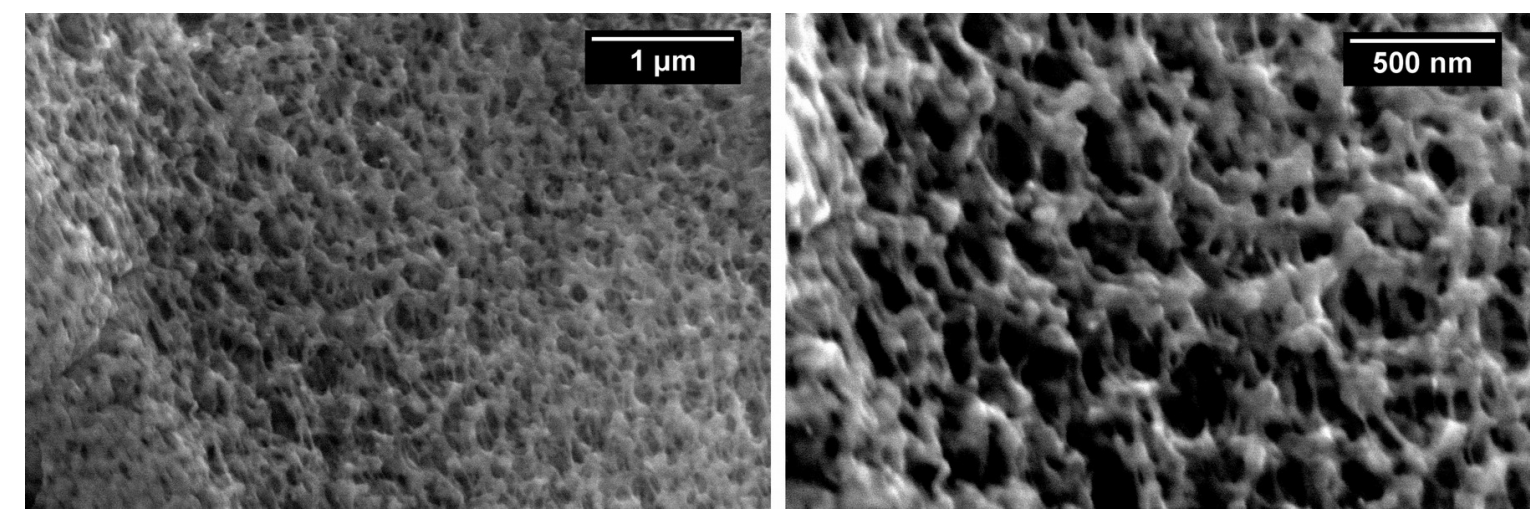

Fig.3. SEM images of chitosan nanoparticles at $1 \mu \mathrm{m}$ and $500 \mathrm{~nm}$.

was observed

that the adsorption rate initially increased rapidly from 5 to $20 \mathrm{~min}$, and

The amount of adsorbent was one of the important parameters that strongly affect the sorption capacity. The dependence of Fe (II) and $\mathrm{Mn}(\mathrm{II})$ ions sorption on nano chitosan was studied by varying the amount of the adsorbent from $0.5 \mathrm{~g}$ to $15 \mathrm{~g}$ while keeping the other parameters such as $\mathrm{pH} 4.0 \pm 0.2$ for Fe (II) ions, $\mathrm{pH} 6 \pm 0.2$ for $\mathrm{Mn}(\mathrm{II})$ ions metal solution volume $(1000 \mathrm{ml})$, concentration $(10 \mathrm{mg} / \mathrm{L})$, and contact time (120 min) constant. Fig.4 (b) show that the removal percentage increases with increasing adsorbent dose from 92\% to 99.8\%.for Fe (II) and from 37.9\%to 95.3\% for $\mathrm{Mn}(\mathrm{II})$ ions. These increases were attributed to increasing the active sites and surface area of the chitosan nanoparticles.

Fig.4 (c) shows the effect of initial concentration of Fe (II) and Mn(II) ions onto removal efficiency, where different concentrations of the metal ions were gently shaken with $0.05 \mathrm{~g}$ of chitosan nanoparticles at $\mathrm{pH}$ of the solution 4 and 6 for Fe (II)and Mn(II) respectively. The figure shows that the removal efficiency of the metal ions decreased from 87 to $49 \%$ and from 44.9 to $27 \%$ for Fe (II) and $\mathrm{Mn}(\mathrm{II})$, respectively as the initial concentration increased from 20, 40, 60, 80, 100 and 120 $\mathrm{mg} / \mathrm{l}$.The removal efficiency decreased with the increase in initial metal ions concentration. The poorer uptake at higher metal concentration was resulted due to the increased ratio of the initial number of moles of metal ions to the vacant sites available in adsorbent sites which resulting in a decrease in the removal of adsorbate.

The study of contact time between adsorbent and adsorbate is necessary during adsorption process to consider the efficiency of desorption and regeneration of the adsorbent. The effect of contact time on metal ions adsorption efficiency is shown in Fig.4(d). It then a steady state was obtained with optimal removal efficiency within about 100 min that reached $86 \%$ and $49 \%$ for Fe (II) and Mn (II), respectively. During the process, the adsorbent surface is progressively blocked by the adsorbate molecules, becoming covered after some time. When this happens, the adsorbent cannot adsorb any more ions[39]. 
GAMAL M. ELKADY, et al.
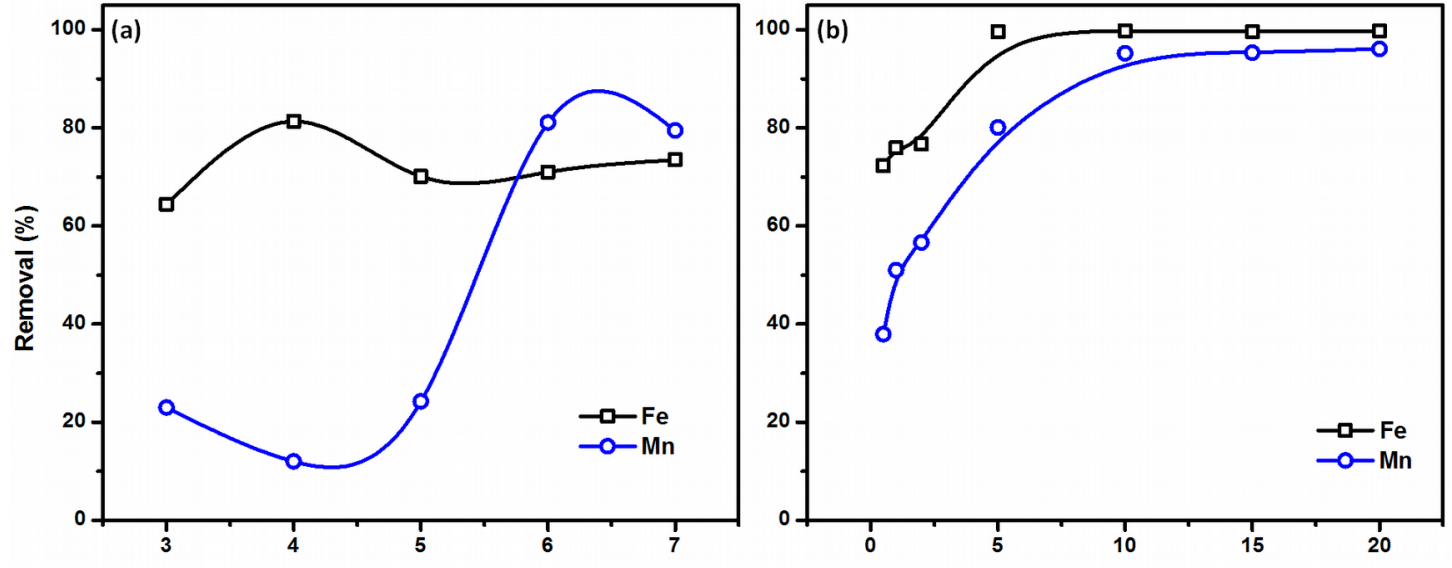

The essential characteristics of the

Langmuir isotherm can be expressed by dimensionless constant called the separation factor $R_{L}$ that calculated as follow;
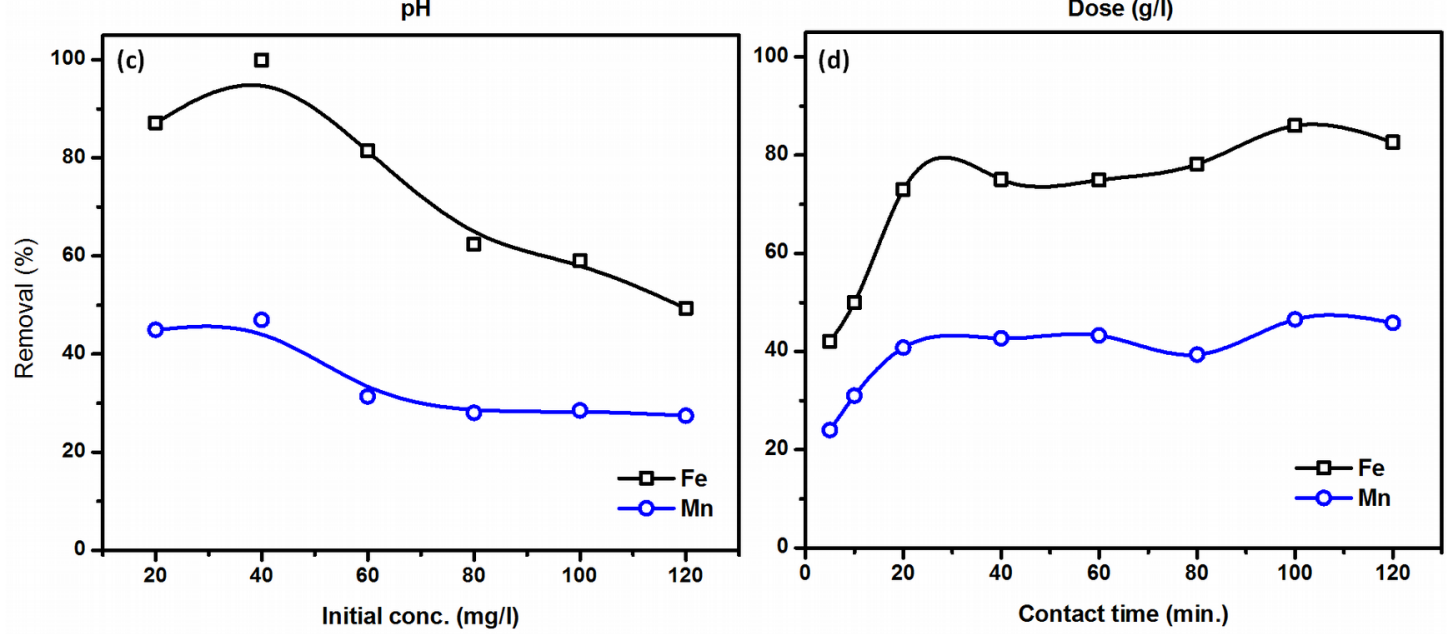

Where, $C_{o}$ is initial concentration of adsorbate (mg/g), $R_{L}$ values indicate the adsorption to be unfavorable when $R_{L}>1$, linear when $R_{L}=1$, favorable when $0<R_{L}<$ 1 and irreversible when $R_{L}=0$.

Fig.4. Effect of different adsorption parameters onto Fe (II) and Mn(II) removal efficiency using NCS adsorbent (a), $\mathrm{pH}$ of the aqueous solution (b), adsorbent dose (c), initial concof metal ions, and (d) contact time

\subsection{Adsorption Isotherms}

Adsorption isotherms are essential in order to determine the adsorption potential of the adsorbent. Figs. (4) show the experimental data of adsorption of Fe (II) and Mn (II) on NCS at different concentrations. However; Langmuir and Freundlich's equations were used to fit the experimental data. The linearized Langmuir adsorption model is shown by the following equation;

$$
\frac{C_{e}}{q_{e}}=\frac{1}{K_{L} q_{m}}+\frac{1}{q_{m}} C_{e}
$$

Where $C_{e}$ is the equilibrium concentration in the solution $(\mathrm{mg} / \mathrm{L}), \mathrm{q}_{\mathrm{e}}$ the amount of metal ion adsorbed on adsorbent NCS (mg/g), $\mathrm{q}_{\mathrm{m}}$ is amount of metal ion for a formation of a monolayer adsorbate on adsorbent surface $(\mathrm{mg} / \mathrm{g}), \mathrm{K}_{\mathrm{L}}$ is Langmuir equilibrium constant that depends on the absorbed energy $(\mathrm{mg} / \mathrm{L})$.
The Freundlich isotherm is another popular isotherm that is used widely to express adsorption equilibrium at constant temperature [7].

The linearized Freundlich adsorption model is shown by the following equation:

$$
\log q e=\log k_{F}+\frac{1}{n}\left(\log C_{e}\right)
$$


REMOVAL OF FE (II) AND MN (II) FROM WASTEWATER ...

Where, $\mathrm{K}_{\mathrm{F}}$ is Freundlich isotherm constant that shows adsorption potential and $\mathrm{n}$ is Freundlich equilibrium constant that expresses the binding energy between the adsorbent and metal ions. The isotherm constants for these models were found by a linear regression and the results are shown in Table2 and Fig.5(a-b)The data values indicate that the adsorption data for Fe (II) and Mn (II) removal fitted well within the Langmuir and the Freundlich isothermal curve for the concentration studied. However, the higher correlation coefficient obtained from Freundlich model $\left(\mathrm{R}^{2}=0.985,0.979\right)$ for $\mathrm{Fe}$ (II) and $\mathrm{Mn}$ (II) respectively compared to
Langmuir curve $\left(\mathrm{R}^{2}=0.93,0.95\right)$ for Fe (II)and $\mathrm{Mn}(\mathrm{II})$, respectively, suggests that the adsorption was taken place on the heterogeneous surface of the adsorbent much better than the monolayer adsorption. The value of $\mathrm{R}_{\mathrm{L}}$ calculated for $\mathrm{Fe}$ (II) and $\mathrm{Mn}$ (II) concentrations was 0.115 and 0.217, respectively, that means the adsorption of both of metal ions on NCS is a favorable process. For the Freundlich constant, $\mathrm{n}$ for Fe (II) and Mn (II) were 2.58 and $1.69 \mathrm{~g} / \mathrm{l}$, respectively, these values of $\mathrm{n}$ represent an appropriate adsorption.

Table 2. Langmuir and the Freundlich equations parameters for removal Fe(II)and Mn(II)

\begin{tabular}{|l|l|l|l|}
\hline \multirow{4}{*}{ Langmuir Isotherm Results } & \multicolumn{1}{|c|}{ parameter } & \multicolumn{1}{|c|}{ Fe(II) } & \multicolumn{1}{c|}{ Mn(II) } \\
\cline { 2 - 4 } & $\mathrm{q}_{\mathrm{m}}(\mathrm{mg} / \mathrm{g})$ & 133.33 & 99.3 \\
\cline { 2 - 4 } & $\mathrm{k}_{\mathrm{L}}(\mathrm{l} / \mathrm{mg})$ & 0.064356 & 0.33665 \\
\cline { 2 - 4 } & $\mathrm{R}^{2}$ & 0.93 & 0.95 \\
\cline { 2 - 4 } & $\mathrm{R}_{\mathrm{L}}$ & 0.115 & 0.217 \\
\hline \multirow{3}{*}{ Freundlich Isotherm Results } & $\mathrm{n}$ & 2.58 & 1.69 \\
\cline { 2 - 4 } & $\mathrm{k}_{\mathrm{F}}$ & 3.807 & 2.442 \\
\cline { 2 - 4 } & $\mathrm{R}^{2}$ & 0.979 & 0.985 \\
\hline
\end{tabular}
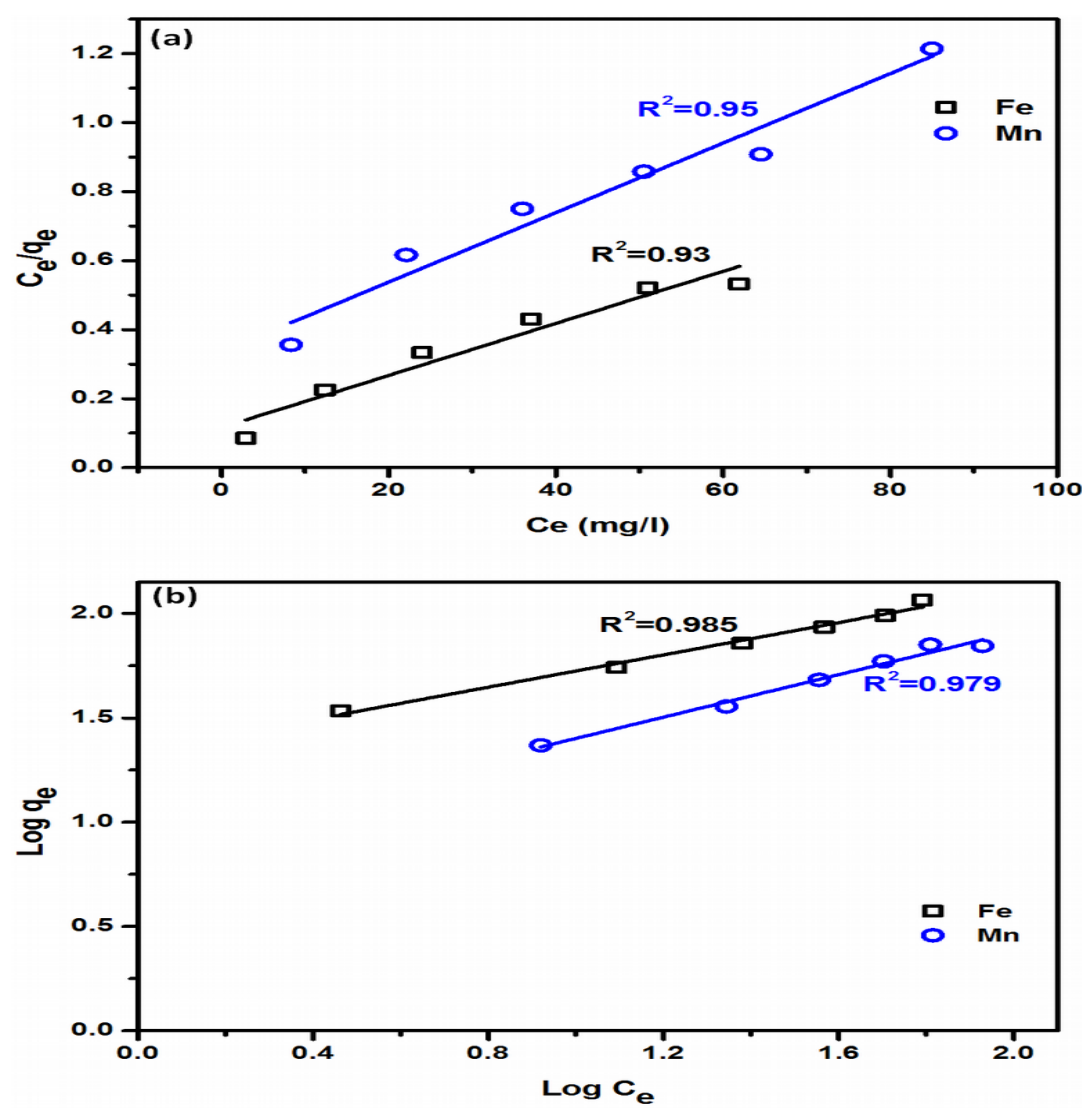

Fig.5. Langmuir (a) and Freundlich (b) isotherm models for the adsorption of Fe and Mn on nanochitosan. 


\subsection{Adsorption Kinetics}

A suitable adsorbent for water treatment must not only have a high capacity but also a fast adsorption rate. Adsorption rate is one of the important properties of adsorbent. Kinetic models are used to survey the controlling parameters of adsorption processes, such as adsorption rate, chemical reaction, and diffusion mechanisms. Fig.6 (a-b) shows the effect of contact time on of $\mathrm{Fe}(\mathrm{II})$ and $\mathrm{Mn}$ (II) adsorption by NCS. For kinetics study, the models of pseudo-first order and pseudosecond order were used. The pseudo-first order model equation is;

$$
\log \left(q_{e}-q_{t}\right)=\log q_{e}-k_{1} t
$$

Where $\mathrm{q}_{\mathrm{t}}(\mathrm{mg} / \mathrm{g})$ is amounts of metal ion adsorbed at time "t", $\mathrm{q}_{\mathrm{e}}$ is amounts of metal ion adsorbed at equilibrium, and $\mathrm{K}_{1}$ is the constant coefficient of pseudo-first-order rate of adsorption $\left(\mathrm{min}^{-1}\right)$.by the value, $\mathrm{k}_{1}$ is obtained by plotting $\log \left(q_{e}-q_{t}\right)$ against $\mathrm{t}$. The linear form of pseudo-second-order model is given by the following equation;

$$
\frac{t}{q_{t}}=\frac{1}{k_{2} q_{e}^{2}}+\frac{1}{q_{e}} t
$$

Where $\mathrm{K}_{2}$ is the rate constant of pseudo-second order adsorption, $\mathrm{k}_{2}$ is also obtained by plotting $\mathrm{t} / \mathrm{q}_{\mathrm{t}}$ against $\mathrm{t}$. The fitted parameters of the two kinetic models are reported in Table (3). The experimental $\mathrm{q}_{\mathrm{e}}$ values for both metal ions were closer to the calculated $\mathrm{q}_{\mathrm{e}}$ values obtained from
Table 3. Kinetic pseudo-first -second order equations parameters for removal $\mathrm{Fe}(\mathrm{II})$ and $\mathrm{Mn}(\mathrm{II})$

\begin{tabular}{|c|l|l|l|}
\hline \multicolumn{1}{|c|}{ Isotherm } & parameter & $\mathrm{Fe}(\mathrm{II})$ & $\mathrm{Mn}(\mathrm{II})$ \\
\hline \multirow{4}{*}{ Pseudo-first-order } & $\mathrm{K}_{1}\left(\mathrm{~min}^{-1}\right)$ & 0.00523 & 0.00362 \\
\cline { 2 - 4 } & $\mathrm{q}_{\mathrm{e}}(\mathrm{mg} / \mathrm{g})$ & 2.8 & 1.82 \\
\cline { 2 - 4 } & $\mathrm{R}^{2}$ & 0.959 & 0.936 \\
\hline \multirow{5}{*}{ Pseudo-second-order } & $\mathrm{K}_{2}$ (g/mg.min) & $5.836 \times 10^{-5}$ & $5.778 \times 10^{-5}$ \\
\cline { 2 - 4 } & $\mathrm{R}^{2}$ & 0.989 & 0.899 \\
\cline { 2 - 4 } & $\mathrm{q}_{\mathrm{e}}$ calc. (mg/g) & 185.873 & 148.588 \\
\cline { 2 - 4 } & $\mathrm{q}_{\mathrm{e}}$ exp. (mg/g) & 116.2 & 70 \\
\hline
\end{tabular}
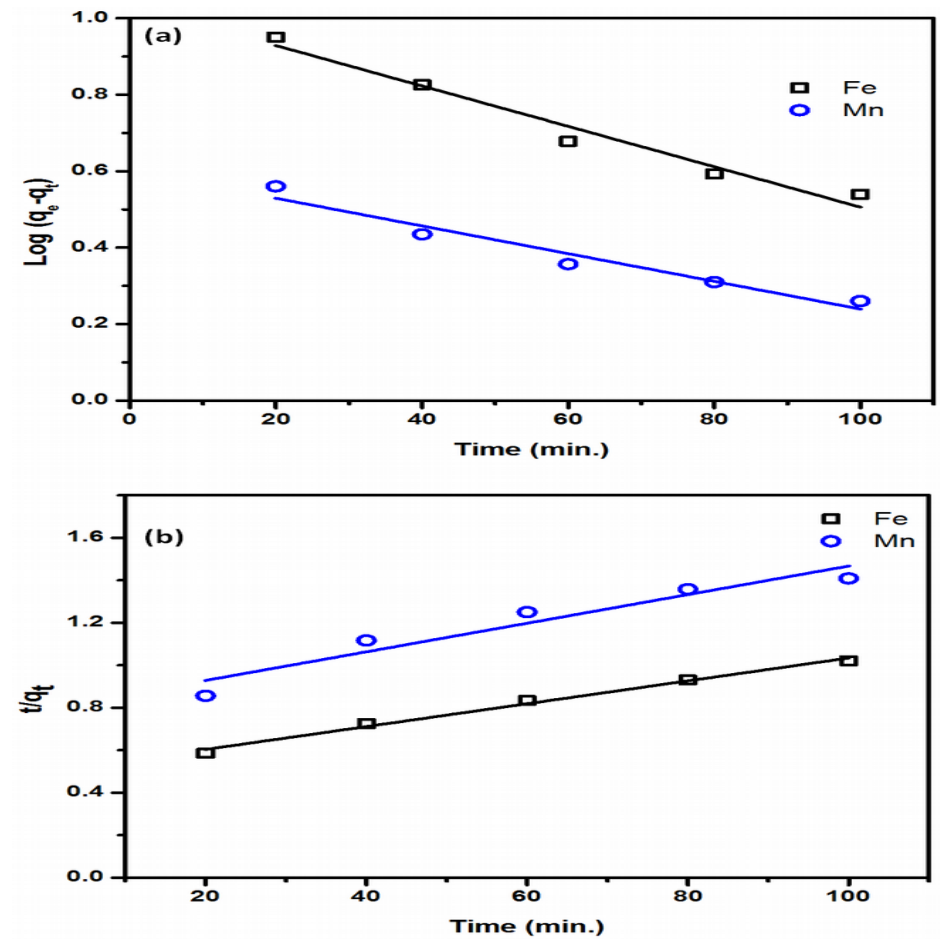

the second order

kinetic plots compared to those of the first order kinetic plots and The values the correlation coefficient $\mathrm{R}^{2}$ for both metal ions from the linear plots show slightly different (Table 3).

These indicated the adsorption kinetics followed the pseudosecondorder kinetics.

Fig.6: (a) Pseudo-first-order kinetic model -(b) Pseudo-second-order kinetic models for the adsorption 


\section{CONCLUSION}

REMOVAL OF FE (II) AND MN (II) FROM WASTEWATER ...

Chitosan is extracted from the locally available shrimp shell waste using inexpensive chemicals with DDA75\% and M.wt 3923 characterized using FTIR and XRD and converted to the nano size by ionic gelation method using TPP to increase its surface area to enhance adsorption capacity characterized using particle size analyzer, TEM and SEM images showed that NCS it was succefuly prepared .batch experiments with different factors include $\mathrm{pH}$, adsorbent dose, initial concentration and contact time used for removal Fe (II)and $\mathrm{Mn}(\mathrm{II})$ and adsorption isotherms Langmuir and Freundlich was used to study the distribution of metal ions on the surface of nano chitosan and pseudo firstsecond order as adsorption kinetics used to know the adsorption rate, the sorption capacity of chitosan nanoparticles is high and the adsorbent favors multilayer adsorption. The kinetics studies show that the adsorption follows the pseudo-second-order kinetics. The choice of chitosan nanoparticles for removal $\mathrm{Fe}$ (II)and $\mathrm{Mn}(\mathrm{II})$ metal ions is considered an economic inexpensive substance used as chemical adsorbent for water treatment

\section{REFERENCES}

1. Reiad, N.A., et al., Adsorptive removal of iron and manganese ions from aqueous solutions with microporous chitosan/polyethylene glycol blend membrane. Journal of Environmental Sciences, 2012. 24(8): p. 1425-1432.

2. Crossgrove, J. and W. Zheng, Manganese toxicity upon overexposure. NMR Biomed, 2004. 17(8): p. 544-553.

3. Vries, D., et al., Iron and manganese removal: Recent advances in modelling treatment efficiency by rapid sand filtration. Water Res, 2017. 109: p. 35-45.

4. Gerente, C., et al., Application of Chitosan for the Removal of Metals From Wastewaters by Adsorption-Mechanisms and Models Review. Critical Reviews in Environmental Science and Technology, 2007. 37(1): p. 41-127.

5. Guibal, E., et al., A Review of the Use of Chitosan for the Removal of Particulate and Dissolved Contaminants. Separation Science and Technology, 2006. 41(11): p. 2487-2514.
6. Liu, C., et al., Efficient removal of Cd(ii) ions from aqueous solutions via visible capturing. RSC Adv., 2016. 6(44): p. 38430-38436.

7. Seyedi, S.M., et al., Comparative Cadmium Adsorption from Water by Nanochitosan and Chitosan. International Journal of Engineering and Innovative Technology (IJEIT), 2013.

8. Gamage, A. and F. Shahidi, Use of chitosan for the removal of metal ion contaminants and proteins from water. Food Chemistry, 2007. 104(3): p. 989-996.

9. Honarkar, H. and M. Barikani Applications of biopolymers I: chitosan. Monatshefte für Chemie - Chemical Monthly, 2009. 140(12): p. 1403-1420.

10. Ahing, F.A. and N. Wid, Optimization of shrimp shell waste deacetylation for chitosan production. International Journal of advanced and applied sciences, 2016. 3(10): p. 31-36.

11. Cacciari, M., M.L. Mangano, and P. Nason, Gluon PDF constraints from the ratio of forward heavy-quark production at the LHC at [Formula: see text] and $13 \mathrm{TeV}$. Eur Phys J C Part Fields, 2015. 75: p. 70-73.

12. Bhumkar, D.R. and V.B. Pokharkar, Studies on Effect of pH on Cross-linking of Chitosan With Sodium Tripolyphosphate: A Technical Note. AAPS PharmSciTech, 2006. 7: p. E1-E6.

13. Kunjachan, S. and S. Jose, Understanding the mechanism of ionic gelation for synthesis of chitosan nanoparticles using qualitative techniques. Asian Journal of Pharmaceutics, 2010. 4(2): p. 148-153.

14. Agarwal, M., D. Nagar, and N. Srivastava, Chitosan Nanoparticles based Drug Delivery. International Journal of Advanced Multidisciplinary Research, 2015. 2: p. 1-13.

15. Fan, W., et al., Formation mechanism of monodisperse, low molecular weight chitosan nanoparticles by ionic gelation technique. Colloids Surf B Biointerfaces, 2012. 90: p. 2127.

16. Ali, S.W., M. Joshi, and S. Rajendran, Synthesis and Characterization of Chitosan Nanoparticles with Enhanced Antimicrobial Activity. International Journal of Nanoscience, 2011. 10(04n05): p. 979-984.

17. Younes, I. and M. Rinaudo, Chitin and chitosan preparation from marine sources. Structure, properties and applications. Mar Drugs, 2015. 13(3): p. 1133-1174.

18. Benhabiles, M.S., et al., Antibacterial activity of chitin, chitosan and its oligomers prepared from shrimp shell waste. Food Hydrocolloids, 2012. 29(1): p. 48-56.

19. Yuan, Y., et al., Deacetylation of Chitosan: Material Characterization and in vitro Evaluation via Albumin Adsorption and PreOsteoblastic Cell Cultures. Materials, 2011. 4(12): p. 1399-1416. 
20. Vaezifar, S., et al., Effects of Some Parameters on Particle Size Distribution of Chitosan Nanoparticles Prepared by Ionic Gelation Method. Journal of Cluster Science, 2013. 24(3): p. 891-903.

21. Qi, L. and Z. Xu, Lead sorption from aqueous solutions on chitosan nanoparticles. Colloids and Surfaces A: Physicochemical and Engineering Aspects, 2004. 251(1-3): p. 183190.

22. Puvvada1, Y.S., Extraction of chitin from chitosan from exoskeleton of shrimp for application in the pharmaceutical industry. International Current Pharmaceutical Journal, 2012.

23. Hossain, M.S., Production and characterization of chitosan from shrimp waste. J. Bangladesh Agril. Univ, 2014.

24. Alishahi, A., et al., Enhancement and Characterization of Chitosan Extraction from the Wastes of Shrimp Packaging Plants. Journal of Polymers and the Environment, 2011. 19(3): p. 776-783.

25. Alsharabasy, A.M., Semi-synthesis of Chitosan with High Molecular Weight and Enhanced Deacetylation Degree. Polymer science, 2016. 02(02).

26. K, B. and R. Ara Begum E, Chitosan A Low Cost Adsorbent for Electroplating Waste Water Treatment. Journal of Bioremediation \& Biodegradation, 2016. 07(03).

27. Radnia, H., et al., Adsorption of Fe(II) ions from aqueous phase by chitosan adsorbent: equilibrium, kinetic, and thermodynamic studies. Desalination and Water Treatment, 2012. 50(1-3): p. 348-359.

28. Zareie, C., Preparation of Nanochitosan as an Effective Sorbent for the Removal of Copper Ions from Aqueous Solutions. International Journal of Engineering, 2013. 26(8 (B)).

29. Chattopadhyay, D.P. and M.S. Inamdar, Studies on Synthesis, Characterization and Viscosity Behaviour of Nano Chitosan. Research Journal of Engineering Sciences, 2012. 1(4): p. 9-15.

30. Ahing , F.A. and N. Wid Extraction and Characterization of Chitosan from Shrimp Shell Waste in Sabah. Transactions on Science and Technology 2016. 3: p. 227 - 237.

31. O-T, W., The infrared spectra of complex molecules. Vol. 1, 3rd. edn., LJ Bellamy, Chapman and Hall, London, 1975, pp. xix+ 433, price£ 8.00. Journal of Molecular Structure, 1976. 34: p. 315-315.

32. Sivakami, M.S., et al., Preparation and characterization of nano chitosan for treatment wastewaters. Int J Biol Macromol, 2013. 57: p. 204-212.

33. Huang, K.-S., Y.-R. Sheu, and I.-C. Chao, Preparation and Properties of Nanochitosan.
Polymer-Plastics Technology and Engineering, 2009. 48(12): p. 1239-1243.

34. Liu, H. and C. Gao, Preparation and properties of ionically cross-linked chitosan nanoparticles. Polymers for Advanced Technologies, 2009. 20(7): p. 613-619.

35. Koukaras, E.N., et al., Insight on the formation of chitosan nanoparticles through ionotropic gelation with tripolyphosphate. Mol Pharm, 2012. 9(10): p. 2856-2862.

36. Vila, A., et al., Low molecular weight chitosan nanoparticles as new carriers for nasal vaccine delivery in mice. European Journal of Pharmaceutics and Biopharmaceutics, 2004. 57(1): p. 123-131.

37. Shekhawat, A., et al., Removal of Cd(II) and $\mathrm{Hg}(\mathrm{II})$ from effluents by ionic solid impregnated chitosan. Int J Biol Macromol, 2017.

38. Hall and Christine, Evaluation of Iron and Manganese Control for a Volcanic Surface Water Supply Treated with Conventional Coagulation, Sedimentation and Filtration Processes. Electronic Theses and Dissertations, 2014.

39. Crini, G. and P.-M. Badot, Application of chitosan, a natural aminopolysaccharide, for dye removal from aqueous solutions by adsorption processes using batch studies: A review of recent literature. Progress in Polymer Science, 2008. 33(4): p. 399-447. 